\title{
The Perceptions of Local Communities towards the Conservation of Birds in an Important Bird Area in Ghana
}

\author{
E. H. Owusu \\ Ghana Wildlife Society, P. O. Box 13252, Accra, Ghana
}

\begin{abstract}
The important bird areas (IBA) concept provides a practical index of the diversity and condition of an ecosystem on a site-by-site basis using birds as indicators. It is believed that protecting and managing such sites will result in the conservation of some of the most sensitive, fragile and ecologically rich habitats in the world. However, acceptance of the IBA concept and, thus, site conservation action, by local communities is dependent on their perception of the importance of birds with regard to some aspects of their livelihood. The study was undertaken to examine the importance local communities around an IBA, the Afadjato and Agumatsa Conservation Area in Ghana, attach to conservation of birds, and their relevance as an indicator of environmental quality. Results obtained from a questionnaire survey, combined with group interviews, suggest that the importance local communities attached to bird conservation in the area was, to a large extent, dependent on the village or locality where people lived.
\end{abstract}

\section{Introduction}

The important bird areas (IBA) concept was developed to advocate the conservation of sites that are nationally and globally important, and considered to be of critical importance for naturally occurring bird populations, as well as biodiversity in general (Birdlife, 1996). The concept also provides a practical index of the diversity and condition of an ecosystem on a site-by-site basis. Therefore, it is believed that conserving and managing such sites will result in the wise use of some of the most sensitive, fragile and ecologically rich habitats in the world (Birdlife, 1996).

The IBA concept was developed in Europe by Birdlife International in 1985 as an objectively defined and practical tool for conservation that would be agreed internationally and applied globally, serving as a means of stimulating the establishment of a protected area network. As a practical tool for conservation, selection of IBA sites is based on the following objectives: (1) they must be sites of international significance for conservation of birds at the global, regional or sub-regional level, (2) they must be practical tools for conservation, (3) they must be chosen on the basis of standardised, agreed criteria applied with common sense, (4) wherever possible, they must be large enough to support self-sustaining populations of those species for which they are important, (5) they will preferentially include, where appropriate, existing protected area networks, and (6) they must form part of a wider integrated approach to conservation that embraces sites, species and habitat protection (Birdlife, 1996).

A limitation, however, is that it is only a component of an integrated approach to the conservation of habitats and sites, and is, therefore, not appropriate for all species.

One such site in Ghana is Mount Afadjato and the Agumatsa Range (Fishpool \& Evans, 2001). This paper examines the importance that local communities around the site attach to conservation of birds and their relevance as indicators of environ-mental quality. It further discusses the need to involve local people in site conservation actions, thereby, eliciting their support for biodiversity conservation.

Study area

\section{Materials and methods}

Mount Afadjato and the Agumatsa Range $\left(0^{\circ} 15^{\prime} \mathrm{E}-0^{\circ} 45^{\prime} \mathrm{E}, 6^{\circ} 45^{\prime}-7^{\circ} 15^{\prime} \mathrm{N}\right)$ are part of the AkwapimTogo Range, which constitute the highest hills in Ghana and are located in the Hohoe Distrcit of the Volta Region. Mount Afadjato itself is the highest mountain in Ghana at $890 \mathrm{~m}$ above sea level. Agumatsa Range runs in a northeast to southwest direction between the Volta River and the Togo border (NtiamoaBaidu et al., 2001). The Agumatsa Range is a distinct landmass with Wli and Tagbo waterfalls at the northern and southern borders, respectively. The study villages (Fig. 1) lie at the foot of the Agumatsa West African Journal of Applied Ecology - Volume 13 
Range and include Gbledi-Gborgame, Gbledi-Chebi, Fodome-Ahor, Wli-Afegame and Wli-Agorviefe, which together cover an area of about $1172 \mathrm{~km}^{2}$. For the purpose of this study, the whole area is referred to as Afadjato and Agumatsa Conservation Area (AACA).

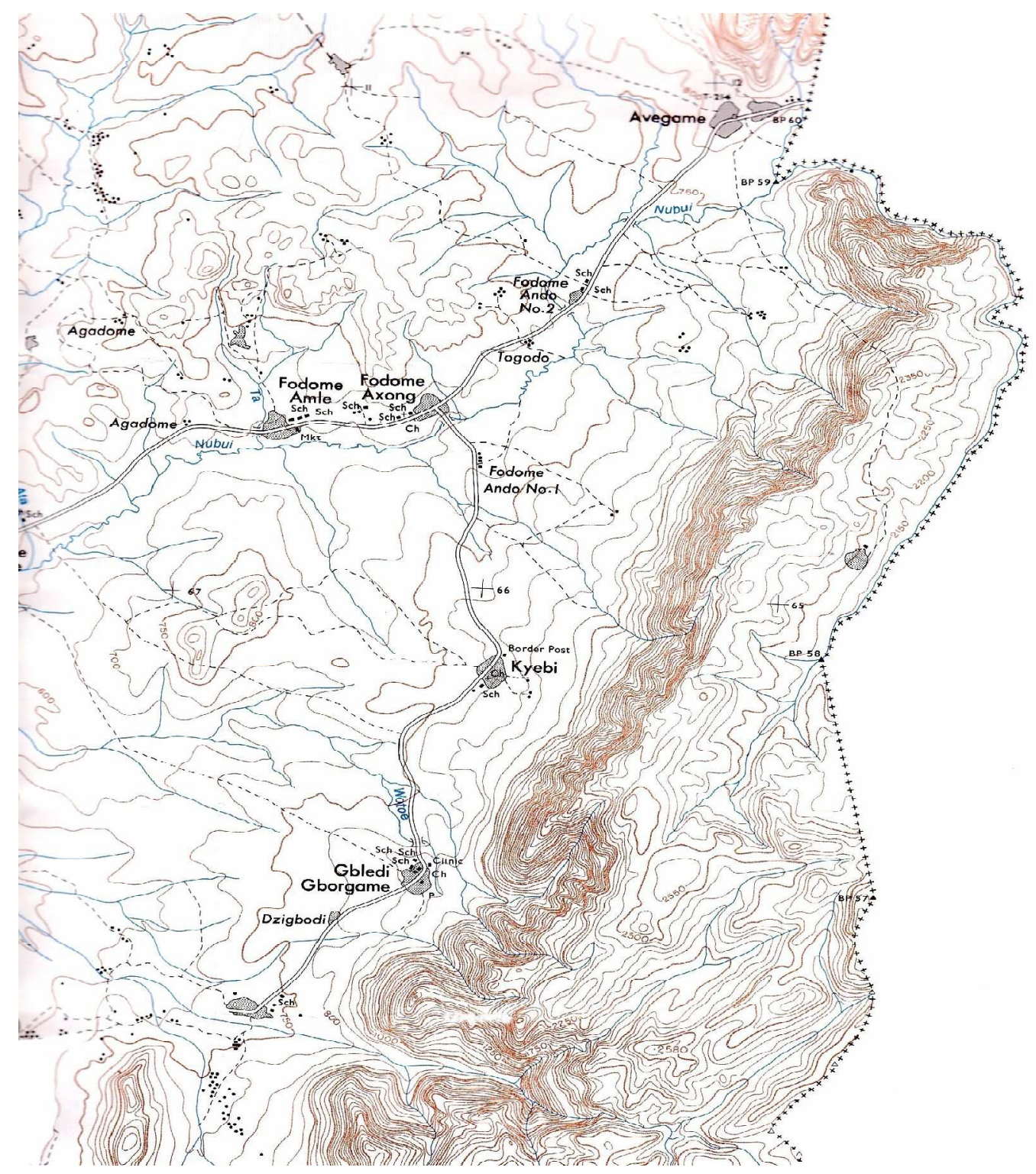

Fig. 1. Study area showing major villages

Individual interviews using structured questionnaires and group discussions were held to collect information on the value of birds to local people, and the importance they attached to bird conservation. Three villages were surveyed, comprising Gborgame, Chebi and Ahor. The selection of villages was based purely on proximity to the IBA site. Fifty individuals were interviewed in each of the villages representing $6.8 \%, 8.1 \%$ and $12.4 \%$ of the populations at Gborgame, Chebi and Ahor, respectively. Group interviews involved bringing together the older people (above age 50) in each of the villages. Through informal discussions, the groups were asked questions which sought to confirm answers given by individuals in the individual interviews.

West African Journal of Applied Ecology - Volume 13 
The perceptions of local people in the three villages were compared using chi-square analysis. A logistic regression analysis was performed to examine which of explanatory factors, notably village, sex, age, educational background and income levels was more likely to determine the local peoples' perceptions of conservation of birds in their area.

\section{Local peoples' perceptions of bird con-servation}

Perceptions of the importance of conserving birds varied among the respondents living in different villages. Respondents in Gborgame attached more importance $\left(\chi^{2}=8.44, \mathrm{df}=2, P<0.05\right)$ to conserving birds than those in the two other villages (Table 1). However, there was no difference in responses in relation to sex, age, educational background and income level of respondents in different villages $(P>$ $0.05)$.

TABLE 1

Perceptions of local people in different villages of the importance of bird conservation

\begin{tabular}{|c|c|c|c|c|}
\hline Village & \multicolumn{2}{|c|}{ Sample size } & Yes $(\%)$ & $\mathrm{No}(\%$ \\
\hline \multicolumn{2}{|c|}{ Gborgame } & 50 & 72.0 & 28.0 \\
\hline Chebi & 50 & 52.0 & 48.0 & \\
\hline Ahor 50 & 44.0 & 56.0 & & \\
\hline Total & 150 & 56.0 & 44.0 & \\
\hline
\end{tabular}

Of those respondents who saw bird conservation as important, the most important reason given differed across villages $\left(\chi^{2}=29.82, \mathrm{df}=3, P<0.001\right)$. Respondents from all the villages agreed that the most important reason (49.4\%) for conserving birds was as a source of meat (Table 2). Other less important reasons given did not differ across villages $\left(\chi^{2}=6.50\right.$, df $\left.=6, P>0.05\right)$ but were that the presence of some bird species indicated (i) the presence of insect crop pests, (ii) the best time to plant crops, and (iii) an omen or good luck (Table 2). However, the opinion held by the people living in the three villages did not differ by sex, age, educational background or income level of respondents $(P>$ $0.05)$.

TABLE 2

Reasons given by local people in different villages for the importance of conserving birds

$\begin{array}{lccccc}\text { Village } & \text { Sample size } & \begin{array}{l}\text { Determine } \\ \text { planting } \\ \text { seasons(\%) }\end{array} & \begin{array}{c}\text { Indicate presence } \\ \text { of insect pests of } \\ \text { crops(\%) }\end{array} & \begin{array}{c}\text { Source of } \\ \text { meat(\%) }\end{array} & \begin{array}{c}\text { Sign of bad omen } \\ \text { or good luck(\%) }\end{array} \\ \text { Gborgame } & 35 & 17.1 & 25.7 & 45.7 & 11.4 \\ \text { Chebi } & 26 & 7.7 & 26.9 & 50.0 & 15.4 \\ \text { Ahor } & 22 & 27.3 & 18.2 & 54.5 & 0.0 \\ \text { Total } & 83 & 16.9 & 24.1 & 49.4 & 9.6\end{array}$

Of those who did not see bird conserva-tion as important, the reasons given showed important difference across villages $\left(\chi^{2}=22.13, \mathrm{df}=2, P<0.001\right)$. Overall, the most common reason $(60.6 \%)$ was that birds were common (Table 3). However, at Ahor, the most common reason was that birds were crop 
pests. This opinion of respondents from Ahor did not, however, differ between the sexes, age, educational backgrounds and income levels of respondents $(P>0.05)$.

TABLE 3

Reasons why local people in different villages believe it is not important to conserve birds

$\begin{array}{lcll}\text { Village } & \begin{array}{c}\text { Sample size } \\ (\%)\end{array} & \begin{array}{l}\text { Crop pests } \\ (\%)\end{array} & \\ & & & \\ \text { Gborgame } & 15 & 26.7 & 73.3 \\ \text { Chebi } & 23 & 8.7 & 91.3 \\ \text { Ahor } & 28 & 71.4 & 28.3 \\ \text { Total } & 66 & 39.4 & 60.6\end{array}$

The importance of bird conservation as perceived by local people

Logistic regression of social factors like locality (village), sex, age, educational back-ground and income level on the perceptions of local people of the importance of bird conservation was significant $(P$ $<0.01$ ), and the model explains $66.2 \%$ of the variance. The model showed that the village where people lived was the most important factor determining the importance attached to the conservation of birds. Hence, people from Gborgame were more likely to consider bird conservation as important, while people from Chebi and Ahor were more likely to have an opposing view. Likewise, people with basic education were most likely to see the importance of conservation of birds (Table 4).

TABLE 4

Factors determining the importance people attached to bird conservation based on logistic regression

\begin{tabular}{|c|c|c|c|c|c|c|}
\hline Variable & $B$ & S.E. & $d f$ & Significance & & \\
\hline \multirow[t]{2}{*}{ Village } & - & - & 2 & $0.005^{* *}$ & Chebi & -1.21 \\
\hline & 0.49 & 1 & $0.014^{*}$ & & & \\
\hline Ahor & -1.56 & 0.49 & 1 & $0.002 * *$ & & \\
\hline Gborgame & - & - & & 0 & & \\
\hline \multicolumn{7}{|l|}{ Sex } \\
\hline Male & -0.25 & 0.40 & 1 & 0.528 & & \\
\hline Female & - & - & - & 0 & & \\
\hline Age & - & - & 3 & 0.267 & & \\
\hline$(20-39)$ & 0.37 & 0.75 & 1 & 0.628 & & \\
\hline$(40-59)$ & 0.93 & 0.71 & 1 & 0.193 & & \\
\hline$(60>)$ & 1.28 & 0.79 & 1 & 0.105 & & \\
\hline$(<20)$ & - & - & - & 0 & & \\
\hline Educational background & - & - & 2 & 0.836 & & \\
\hline Basic & 1.19 & 0.56 & 1 & $0.034 *$ & & \\
\hline Secondary & 0.58 & 0.71 & 1 & 0.419 & & \\
\hline No formal education & - & - & - & 0 & & \\
\hline Income level & - & - & 2 & 0.581 & & \\
\hline Average & 0.27 & 0.80 & 1 & 0.734 & & \\
\hline High & 0.33 & 0.40 & 1 & 0.420 & & \\
\hline Low & - & - & - & 0 & & \\
\hline
\end{tabular}

West African Journal of Applied Ecology - Volume 13 


\section{Attitudes towards bird conservation}

\section{Discussion}

Most Ghanaian communities see birds as a very common faunal group, and so they do not pay particular attention to birds. This perception is reflected in reasons given to some answers on why birds should not be conserved. Birds are very common and can be found everywhere, so there is no need to spend time and energy on bird conservation, especially given that birds can sometimes be crop pests and a nuisance. Respondents from Ahor village could have stressed this reason because the interview was conducted at a time when most of their rice farms were under attack by bird pests making them spent several hours on the farms to scare the birds away.

Local people, however, recognise the importance bird conservation. The major reason was the use of such birds as Francolins as food by the local people. This perception of birds is common in most societies throughout the world. For example, it is believed that birds contribute $2.5-3 \%$ to the food of forest dwelling people in the Amazon (Diamond, 1987). The other reasons are mostly based on the role of birds as sources of information about certain events in the local community. For example, honey guides (all members of the family Indicatoridae) reveal the source of honey, pied crows (Corvus albus) indicate the coming of rains and owls, particularly, the barn owl (Tyto alba) indicate danger, or are signs of a bad omen, particularly when they appear frequently.

In many rural African communities owls are seen as witches (Isack, 1987; Ntiamoa-Baidu, 1989), and nobody will go near them or touch them. The presence of large numbers of the grasshopper buzzard (Butastur rufipennis) indicates a possible outbreak of locusts that attack their crops. Huge flocks of starlings, particularly the splendid glossy starling (Lamprotornis purpureus) seen between January and March is a signal of the beginning of the farming season. Ntiamoa-Baidu (1995) observed that if wild species are considered as pests, or if people have an aversion to a particular species as a result of traditional beliefs and superstitions, conservationists have the added problem of changing people's attitudes. Under such circumstances, some positive aspects must be found, which can be highlighted and used in conservation messages.

\section{Implications for conservation of Mt Afadjato and the Agumatsa Range}

Some areas for biodiversity conservation have come about proactively rather than reactively (Swaine $e t$ al., 1999). The case of the Afadjato and Agumatsa Conservation Area can be considered to be both proactive and reactive. Local initiative was a precursor of the studies that found the site to be worth conserving. Bird species of conservation concern occurring in the area complement other species belonging to different taxa that are equally important and that could be used as a basis for conservation action. For example, the mountain ranges in the Volta Region, including Mt Afadjato and the Agumatsa Range, have a very rich butterfly fauna and a significant diversity of endemic butterfly (Larsen, 1994; Gordon, 1999; Ntiamoa-Baidu et al., 2001). The forest on the mid-slopes of the mountain also has a genetic heat index of 116, which is substantially higher than several forest reserves in Ghana (Swaine et al., 1999; Ntiamoa-Baidu et al., 2001). Consequently, the site, which is threatened by perennial bush fires, has been identified as a priority site for national conservation action (Ntiamoa-Baidu et al., 2001; Owusu, 2001). However, the conservation of the site should not conflict with local priorities, which is one of the major requirements for local support for conservation. Furthermore, it has been suggested that values of natural resource and goals of conservation ought to be made explicit and agreed as broadly as possible at the beginning of any particular selection of a site for conservation, if conflicts are to be minimised (Williams, 1999).

\section{Conclusion}

West African Journal of Applied Ecology - Volume 13 
A number of species in different categories of conservation concern have been recorded at the study site, qualifying it as an IBA (Ntiamoa-Baidu et al., 2001). For IBA sites to be more valuable and appreciated by local fringe communities, the concept will have to extend beyond birds to site actions that impact positively on the lives of local people. However, selection of sites for conservation action depends on many factors. Williams (1999) observed that conservation is about ensuring the persistence of value. Thus, area selection for conservation is about the 'where first' of in situ conservation action, rather than 'how' and the emotive issues of values, goals and priorities.

\section{Recommendations}

The keen interest shown by local people in the conservation of the forest on Mount Afadjato and the Agumatsa Range offers a very good opportunity and a potential role of impacting positively on conservation of species in the various taxonomic groups, including birds. However, the guaranteed support of local people will depend on how well the importance of species conservation and conservation actions in general are packaged in conservation education programmes. This will require emphasis on potential benefits without raising local peoples expectations beyond what can be achieved. The study shows clearly that attitudes towards bird and forest habitat conservation are, to a large extent, dependent on the inhabitants of villages fringing the Agumatsa Range. Negative attitudes from any group of people are likely to affect any conservation actions that would be put in place at the site. A lot of effort, therefore, will be needed to arouse the interest of non-receptive communities. A good communica-tion plan that is able to turn negative perceptions into positive impacts is, therefore, advocated.

\section{Acknowledgement}

The author wishes to thank the staff of the Ghana Wildlife Society, particularly the forest guards at the Mt Afadjato Community Nature Reserve and Mr Edem Ekpe, the Project Officer, for their support during data collection. The co-operation of local community members of the Gbledi Traditional Area is greatly appreciated. Funding for this study was partially supported by the Royal Netherlands Embassy under the Mt Afadjato-Agumatsa Community Conservation Project.

\section{References}

Birdlife International (1996). Important Bird Area in Africa, IBA Criteria, Categories and Thresholds. Birdlife International, Cambridge.

Diamond A. W. (1987). A Global View of Cultural and Economic Uses of Birds. In The Value of Birds. (A. W. Diamond and F. L. Filion, ed.) Technical Publication 6. International Council for Bird Preservation, Cambridge.

Fishpool, L. D. C. and Evans M. I. (ed.) (2001). Important Bird Areas in Africa and Associated Islands: Priority Sites for Conservation. Pisces Publications and BirdLife International (BirdLife Conservation Series No.11), Newbury and Cambridge.

Gordon I. (1999) Survey of Butterflies and other Insects of Conservation and Economic Interest and Feasibility Studies for Butterfly Farming, Afadjato Community Nature Reserve. Report prepared for the Ghana Wildlife Society (GWS).

Isack H. A. (1987). The cultural and economic importance of birds among the Boran people of northern Kenya. In The Value of Birds. (A. W. Diamond and F. L. Filion, ed.) Technical Publication 6. International Council for Bird Preservation, Cambridge.

Larsen T. (1994). The butterflies of Ghana - their implications for conservation and sustainable use. Ghana Wildlife Department. (Unpubl. report.)

Ntiamoa-Biadu Y. (1989). Granivorous bird pest problem in Tono, Upper East Region, Ghana. Report submitted to the Irrigation Company of Upper East.

Ntiamoa-Baidu Y. (1995). Conservation education in threatened species management in Africa. Bird Conservation International 5: $455-462$.

Ntaimoa-Baidu Y., Owusu E. H., Daramani D. and Nuoh A. A. (2001). Ghana. In Important Bird Areas in Africa and Associated Islands: Priority Sites for Conservation. (L. D. C. Fishpool and M. I. Evans, ed.) Pisces Publications and Birdlife International (Birdlife Conservation Series No.11). Newbury and Cambridge.

Owusu E. H. (2001). Community-based conservation in Ghana: the potential of the Afadjato and Agumatsa Range for ecotourism. (PhD Thesis.), University of Kent, Canterbury, Kent.

Swaine M. D., Ekpe P., Seku F. and Abu-Juam M. (1999). Vegetation Survey of the Mt Afadjato Community Forest Conservation Project. Report prepared for the Ghana Wildlife Society (GWS), Accra, Ghana.

West African Journal of Applied Ecology - Volume 13 
Williams P. H. (1999). Key sites for conservation: area-selection methods for biodiversity. In Conservation in a changing world: integrating processes into priorities for action. (G. M. Mace, A. Balmford and J. R. Ginsberg, ed.) Cambridge University Press, Cambridge. 